\title{
Self-performed supragingival biofilm control: qualitative analysis, scientific basis and oral-health implications $\$$
}

\begin{abstract}
Sheila Cavalca Cortelli(a)
José Roberto Cortelli(a)

Davi Romeiro Aquino(a)

Fernando Oliveira Costa ${ }^{(b)}$
\end{abstract}

(a) PhD, Professor, Department of

Periodontology, Dental School, University of

Taubaté, Taubaté, SP, Brazil.

(b) $\mathrm{PhD}$, Professor, Department of Periodontology, Dental School, Federal University of Minas Gerais, Belo Horizonte, MG, Brazil.

\$Paper presented at the "Promotion of Oral Health in the Public and Private Context" National Symposium, held at the $15^{\text {th }}$ Congress of the Brazilian Association for Oral Health Promotion (ABOPREV), May 27-29, 2010, Brasília, DF, Brazil.

\section{Corresponding author:}

Sheila Cavalca Cortelli

Rua Professor Nelson Freire Campelo, 343,

Jd. Eulália

Taubaté - SP - Brazil

CEP: 12010-700

E-mail: cavalcacortelli@uol.com.br

Received for publication on Jul 07, 2010 Accepted for publication on Jul 26, 2010

\begin{abstract}
Patients frequently fail to achieve an optimal mechanical plaque control. However, many patients are not confident about using mouthrinses, and many professionals refuse to prescribe them for regular daily use. Aiming at achieving a better understanding of the use and prescription of mouthrinses in periodontics, 24 dentists with different dental educational levels were purposively chosen and interviewed in a qualitative research. Partial data was presented at the $15^{\text {th }}$ Congress of the Brazilian Association for Oral Health Promotion (ABOPREV), and full data was presented at the $88^{\text {th }}$ General Session and Exhibition of the International Association for Dental Research (IADR). The professionals' answers were confirmed or rejected through scientific data analysis. Additionally, scientifically supported answers were provided for the interviewees' most frequent unanswered questions. Around half of the participants $(46 \%)$ reported that they recommended the use of mouthrinses, although a high percentage $(64 \%)$ of the dentists answered that they knew very little about the efficacy of mouthrinses and also about the oral benefits $(54 \%)$ provided by them. All interviewees reported that they were aware of the fact that their patients, and themselves, failed to floss and, less frequently, to brush their teeth, and all of them believed that oral health impacts overall systemic health. Seventy five percent answered that using mouthrinses was safe. Most participants (55\%) did not declare themselves as mouthrinse users. We concluded that dentists with different levels of dental education have only partial knowledge related to mouthrinse use in periodontics. The use of effective mouthrinses on a daily basis is justified and can help patients achieve or maintain a healthier mouth. A healthier mouth will positively impact patients' quality of life and could also benefit their overall systemic health.
\end{abstract}

Descriptors: Mouthwashes; Qualitative Research; Oils, Volatile; Chlorhexidine; Cetylpyridinium.

\section{Introduction}

Gingivitis and periodontitis are common diseases related to dental biofilm, affecting many people worldwide. Because both share the same primary etiological agent, the daily control of supragingival biofilm still plays a key role in controlling periodontal inflammation. ${ }^{1}$

Although a downward trend has been observed in the prevalence of periodontitis, ${ }^{2}$ periodontal diseases, mainly gingivitis, still affect differ- 
ent groups, even in developed countries. ${ }^{3}$ Therefore, even assuming that the usual self-performed mechanical biofilm control is effective to a certain extent, periodontal epidemiological data lead us to believe that this control has not been enough, at least for many of our patients. An even more likely assumption would be that flossing and brushing have not been properly performed. ${ }^{4,5}$ Patients frequently fail to achieve an optimal plaque control for many different reasons, ${ }^{6}$ which could contribute to the persistently high prevalence observed of gingivitis and periodontitis. On the other hand, there are many reports about clinical and microbiological additional benefits associated to mouthrinse use. ${ }^{7,9,9,10,11,12,13}$ Another reason that justifies the use of mouthrinses is that this system can deliver an antimicrobial agent in different areas in the mouth that are colonized by microorganisms.

In recent years, maintaining a healthy mouth has become more important. Therefore, the reasons for using a dentifrice, a toothbrush and a mouthrinse should be re-interpreted. Owing to the great development of periodontal medicine, the connection between periodontal status and systemic conditions has been demonstrated..$^{14,15,16,17,18}$ Furthermore, the periodontal health impact on subjects' quality of life has been reported, ${ }^{19,20,21}$ even for special care individuals. ${ }^{22}$ Acceptance of this mouth-body connection fits better the complex definition of health. ${ }^{23}$ Gillon proposed many years ago ${ }^{24}$ that the traditional World Health Organization's definition of health as "a state of complete physical, mental, and social wellbeing and not merely the absence of disease or infirmity" is too broad to be applied in patient care. In any event, viewing oral health as part of overall systemic health puts oral biofilm control, albeit indirectly, in a new scenario.

Among the possible active ingredients, in Brazil most of the commercially available mouthrinses contain chlorhexidine, a fixed combination of essential oils, cetylpyridinium chloride or triclosan. In periodontics, for short-term use, chlorhexidine is the most effective therapeutic agent while the others are mainly directed to regular long-term daily use. However, considering these daily-use agents, essential oils mouthrinses have demonstrated greater anti-plaque and anti-gingivitis properties. Actually, triclosan seems to be an effective agent in dentifrices when combined with a copolymer. ${ }^{25,26}$ Many efforts have been made to improve the expected benefits and help patients to comply with oral rinsing.

Qualitative methods were developed particularly in sociology and anthropology, and are mainly based on in-depth observation, interviews and small group processes. After a long pathway of quantitative research in the early 1990, qualitative research has been accepted with increasing frequency in medical journals. The goal of qualitative research has been defined as "the development of concepts which help us to understand social phenomena in natural (rather than experimental) settings, giving due emphasis to the meanings, experiences, and views of all the participants". ${ }^{27}$ According to Huston and Rowan, ${ }^{28}$ it is conducted by researchers because qualitative tools can answer questions that quantitative methods cannot. It focuses on understanding experiences, attitudes, and behaviors which have a profound effect on patients' perception of health, health-seeking behavior, and adherence to treatment. On the other hand, these usually underestimated aspects also influence professional treatment decisions.

In relation to oral care, many patients are not confident about using mouthrinses, and many professionals refuse to prescribe them for regular daily use, despite the increasing scientific evidence that supports their anti-plaque and anti-gingivitis properties. Considering that this refusing attitude could not be sustained by literature, the authors supposed that a qualitative research method could better identify the reasons for professionals' choices. Moreover, patients' confidence is partially dependent on professionals' knowledge. Therefore, this paper will confirm or reject professionals' choices through scientific data analysis. Also, this paper will provide scientifically supported answers for the interviewees' most frequent unanswered or not precisely answered questions.

\section{Methods Interviews}

Although qualitative research is frequently based on grounded theory and phenomenology, in the pres- 
ent paper it was used to systematically organize data into a structured format. Partial data was presented at the $15^{\text {th }}$ Congress of the Brazilian Association for Oral Health Promotion (ABOPREV), and full data was presented at the Satellite Symposium which took place at the $88^{\text {th }}$ General Session \& Exhibition of the International Association for Dental Research (IADR). As usual, a small group of 24 dentists were purposively chosen and interviewed, three in each of the following educational levels:

a. CNPq (The National Council for Scientific and Technological Development) certified researcher

b. Graduate and undergraduate professor

c. Graduate professor

d. Undergraduate professor

e. Periodontics specialist

f. Specialist in a different area

g. General dentist graduated for longer than five years and

h. General dentist graduated for five years or less Participants were males or females, aged 20 to 50 , living and working in the southeast of Brazil and graduated from public or private Dental Schools.

For the development of this survey, after Ethics Committee approval (protocol \# 358/10), cognitive interviews were performed to obtain the interviewees' opinion related to mouthrinses. Interviews were performed one-to-one, face-to-face or through the internet (always using a webcam), at the place and time chosen by interviewees. Both interviewee and interviewer were alone at the time of the interview. Each dentist was asked to complete the entire survey instrument (composed of open-ended questions) and was aware of the reasons why the research was conducted. No interview was repeated and only one dentist refused to be interviewed. The interviews were audio-recorded, and additional notes were taken during the interview and immediately after its end. Participants were given the opportunity to send e-mails to provide any additional comments to their answers.

The interviewer was a $\mathrm{PhD}$, female dentist, specializing in periodontics, who works mainly as a professor and clinical researcher, with prior teaching and researching experience in the chemical control of biofilm.
The data was analyzed by one researcher and the answers were compared to those supported by published papers found in electronic scientific databases. For each question, the most frequent (\%) answer was compared to literature. In addition, the most frequent unanswered or not precisely answered questions were also compared to literature.

The research question as well as the questions posed to the interviewees and classified in two subsequent hierarchical levels are shown below:

\section{Focus question}

\section{Understanding the use and prescription of mouthrinses in periodontics by professionals with different levels of dental education.}

A. Considering your educational background, please choose one of the options below:

( ) CNPq certified researcher

( ) Graduate and Undergraduate Professor

( ) Graduate Professor

( ) Undergraduate Professor

( ) Periodontics Specialist

( ) Specialist in a different area

( ) General Dentist graduated for longer than five years

( ) General Dentist graduated for five years or less

B. Please choose, among the options below, which best fits your professional activity:

( ) Teaching and research

( ) Teaching

( ) Research

( ) Private practitioner

( ) Public worker

( ) Industry

\section{Sub-hierarchical level 1 questions:}

a. Do you prescribe the use of mouthrinses?

b. Do you know which mouthrinse to prescribe?

c. Do you have information on the effectiveness of mouthrinses?

d. Do you know when to prescribe mouthrinses?

I. If you prescribe their regular use, answer the following queries about this prescription: 
1. when?

2. how?

3. why?

II. If you prescribe their sporadic use, answer the following queries about this prescription:

1. when?

2. how?

3. why?

e. Do you know how to prescribe the use of mouthrinses?

f. Do you know the reason why mouthrinses should be used?

g. Are you aware of the benefits of mouthrinses?

h. Do you know which patients can use mouthrinses?

i. Do you know which patients should use mouthrinses?

\section{Sub-hierarchical level 2 questions:}

- Are you aware of the main active ingredients found in common commercially available mouthrinses?

- Which ingredients?

- Names:

- Is any product superior to others?

- Which product?

- Do you know the posology?

- If so, describe it:

- No

- A little

- Should the product be used before or after toothbrushing?

- Do you know the epidemiology of gingivitis and periodontitis?

- How frequently does gingivitis occur?

- How frequently does periodontitis occur?

- Are you aware of patients' failure in performing mechanical plaque control (toothbrushing and flossing)?

- How often do your patients brush their teeth?

- How often do your patients floss?

- Do they brush their teeth properly?

- Do they floss properly?

- Do you think people comply with the use of mouthrinses?

- Do you know why patients use mouthrinses?
- If you do not recommend or are against the use of mouthrinses. can you explain why?

- Do you believe that systemic conditions (like diabetes) justify the use of mouthrinses?

- Do you believe that oral health can influence overall systemic health?

- Do you have information about the anti-plaque effects of mouthrinses?

- Do you have information about the anti-gingivitis effects of mouthrinses?

- Do you have information about the safety of mouthrinses?

- Do you recommend mouthrinses to people in your family or to those you love?

- Do you use mouthrinses?

Each answer was individually compared to literature because the authors know that the language used may affect how dentists understand questions, and the reader should consider that sometimes the same question was asked in different manners.

\section{Results and discussion}

Half of the participants $(46 \%)$ reported that they recommended the use of mouthrinses, and $90 \%$ reported that they knew which product could be indicated. However, the first discrepancy arose when only $33 \%$ answered that they had information about mouthrinse effectiveness, especially considering that $73 \%$ answered that they knew why to use a mouthrinse and also considering that $63 \%$ reported that they were aware of the benefits of mouthrinses. There are many literature reviews that evaluated the influence of mouthrinses in self-performed plaque control. All of them came to similar conclusions, which supported the prescription of mouthrinses as a useful tool for a better oral health. ${ }^{7,8,12}$ Therefore, it is expected that in the near future the number of dentists who prescribe mouthrinses in Brazil will be higher.

Dentists were asked about the active ingredients of mouthrinses and they answered: chlorhexidine; thymol, menthol, eucalyptol and methyl salicylate; cetylpyridinium chloride, triclosan as well as fluoride. In Brazil these are the most common agents in commercially available mouthrinses. In periodon- 
tics, fluoride is used as part of caries prophylaxis. ${ }^{29,30}$ In addition, the combination of triclosan and copolymer seems to be effective in dentifrices. ${ }^{25,26,31}$ Therefore, the present survey focused on chlorhexidine (CHX), a fixed combination of essential oils (EO) and cetylpyridinium chloride (CPC).

\section{Reasons for mouthrinse use}

Despite its low cost and essential role in preventing gingivitis and periodontitis, patients fail to achieve the required level of mechanical plaque control. ${ }^{4}$ All interviewees reported to know that their patients and themselves fail in flossing and, less frequently, in brushing. Literature points to the fact that brushing alone has limited access to interproximal areas. Therefore, additional devices such as dental floss are required. ${ }^{32}$ Because patients do not adhere well to flossing, ${ }^{33}$ they end up deriving the same benefits as those patients who only use a toothbrush. On the contrary, mouthrinses have been proving to be effective against plaque and gingivitis when considering interproximal sites, sometimes showing similar and even better efficacy levels than those provided by dental floss. ${ }^{34,35,36}$

Most participants (82\%) reported that their patients brushed from 2 to 3 times a day, and $64 \%$ reported that their patients flossed from 1 to 3 times a week. Brushing at least twice a day has been suggested as an appropriate frequency. ${ }^{37,38}$ Although not the desired frequency, the last finding is consistent with the literature that demonstrated that, not only in Brazil ${ }^{39,40}$ but in many countries, patients do not floss on a daily basis, ${ }^{41,42,43}$ even considering dental students. ${ }^{44}$

Compliance is important in achieving a successful outcome of the daily use of any dental care device. Although the word compliance is still applied, adherence seems to be a more powerful term because it implies a willing and autonomous attitude of patients towards health care. Unfortunately, no more than $50 \%$ of patients are highly compliant with recommended oral hygiene procedures, and even those who comply with the treatment do not do it for more than 30 days. ${ }^{45}$ Although all of our interviewees pointed to a lack of adherence to brushing and flossing, $82 \%$ believe that patients adhere well to mouthrinse use. Sixty four percent of participants were not able to answer why people do not adhere to oral care properly. This professional lack of knowledge is not supported by literature in two aspects. The first is that there are known reasons for a decrease in compliance. ${ }^{33}$ The second is that there are published papers that emphasized the need for a better understanding of non-compliant patients including their psychological aspects. ${ }^{46,47}$

Only a small percentage of total mouth area will be clean even after the use of dental floss, toothbrush and tongue cleaner. ${ }^{48,49}$ Among these unclean surfaces many are colonized by bacteria since early childhood. ${ }^{50}$ However, in the present survey only $27.3 \%$ of professionals stated that the cleaning of sites other than teeth and tongue was a reason to prescribe mouthrinses, which is inconsistent with scientific data. Therefore, additional efforts should be made to generalize this specific knowledge among dentists.

Considering that plaque control is crucial for the prevention of periodontal disease, the reported failure in mechanical plaque control partially explains why in many countries there is still a high occurrence of gingivitis and periodontitis. Only $45 \%$ of professionals knew about periodontal epidemiological data. Seventy three percent answered that gingivitis occurred at a high frequency, and $73 \%$ answered that the occurrence of periodontitis was also high. There are no reasons to justify the low percentage of professionals who were acquainted with the epidemiology of periodontal health. On the other hand, the answers acknowledging the high occurrence of gingivitis and periodontitis are consistent with the related literature. Although a downward trend has been observed in the prevalence of periodontitis in the last few years, ${ }^{2}$ periodontal diseases, mainly gingivitis, still affect different age groups, even in developed countries. ${ }^{3,51}$ However, in developing countries such as Brazil, gingivitis and periodontitis are more prevalent and severe. ${ }^{52,53}$

In this context, effective mouthrinses can be used as an adjunct to mechanical plaque control. They can partially fulfill patients' needs related to self-performed oral hygiene procedures, and also help professionals in recommending more effec- 
tive preventive oral care programs. ${ }^{54}$ In addition, in recent years the need for a healthier mouth has become more important. The fact that a poor periodontal health alters indicators of quality of life and could be associated with systemic disorders has been changing patients' self-perceptions and professionals' search for a better periodontal status. In a cross-sectional study, periodontal disease negatively impacted the quality of life of a convenience sample of 401 patients aged 19 to $71 .^{21}$ In addition, poor periodontal health affected smiling patterns and the smile-related indicators of quality of life, which interfere in patients' social relations. ${ }^{20}$ Finally, standard dental care improved self-perceived quality of life. ${ }^{55}$

Populational studies have been conducted worldwide and have found associations between periodontal diseases and cardiovascular disease, ${ }^{56}$ diabetes mellitus ${ }^{57}$ and pneumonia. ${ }^{58}$ In addition, literature reviews published by different authors also support the conclusions of the studies conducted in different populations..$^{14,15,17,18,59}$ In 2008, Weidelich et al. ${ }^{16}$ reviewed Brazilian studies and found 20 on periodontal medicine. The associations observed in other populations were also found in Brazil. Similarly to other authors, this group has also demonstrated the need for additional studies, mainly interventional ones. Since the control of the gingival inflammatory process is associated with a decrease in the risk of some systemic conditions, it seems reasonable that an appropriate oral hygiene program may contribute to individuals' systemic health. A national population-based survey was conducted in Scotland by interviewers who visited eligible households and evaluated 11,869 men and women. Oral health behavior was assessed in all survey years from self-reported frequency of visits to a dentist and of toothbrushing. The results confirmed and further strengthened the suggested association between oral hygiene and the risk of cardiovascular disease. Furthermore, inflammatory markers were significantly associated with poor oral health behavior. ${ }^{60}$ Fujita et al. ${ }^{61}$ demonstrated that a lower frequency of daily toothbrushing was related to higher prevalence of diabetes mellitus and to higher prevalence of hypertension. In intensive care units, the inclusion of chlorhexidine as part of the oral hygiene decreases the number of pneumonia cases associated with mechanical ventilator. ${ }^{62}$ However, the systemic effect of self-performed daily plaque control improved by the inclusion of adjunctive mouthrinses should be tested.

Many reasons to explain why patients rinse were given. The most frequent were: to have a clean mouth $(27 \%)$ or to have a healthier mouth $(27 \%)$. Both reasons are consistent with available scientific findings.

\section{How to use and when to indicate mouthrinses}

In the first hierarchical level, one question was related to the regular or sporadic recommendation of mouthrinses. Around 27\% recommend them for regular use, $27 \%$ recommend them for sporadic use and a majority of $46 \%$ follows both types of mouthrinse recommendation. However, in the next level of questions we could observe that although most interviewees $(82 \%)$ named active ingredients for both regular and sporadic use, they were unable to give posology and prescription information properly. For example, CHX was the only name of an active ingredient given by participants who reported to recommend mouthrinses just for regular use. On the other hand, EO and CPC were informed as options by dentists who rarely recommend mouthrinses and recommend them only in the first week after surgery.

All interviewees reported that patients should rinse twice a day but almost no data was given related to amount $(\mathrm{mL})$ and duration of each rinsing. Supported by the lack of consistent information related to posology/dosage, the authors decided to check whether the labels of the products gave enough information or not. There are two main $0.12 \%$ CHX mouthrinse manufacturers in Brazil. In both labels we found the volume to be rinsed $(15 \mathrm{ml})$, the number of times a day (twice), but there was no guidance about duration of rinsing. The EO (0.064\% thymol, $0.042 \%$ menthol, $0.092 \%$ eucalyptol and $0.06 \%$ methyl salicylate) label gave the volume to be rinsed $(20 \mathrm{ml})$, the duration of rinsing (30 seconds) and the number of times a day (twice). Finally, $0.05 \%$ CPC (or $0.07 \%$ ) is found in several 
mouthrinses, but not all manufactures provided the posology in the label. Although not in all cases, the authors could find directions for rinsing $20 \mathrm{ml}$ twice a day. However, the duration of rinsing was given as 30 seconds or 1 minute. Therefore, in this aspect the authors concluded that there are reasons which partially explain why professionals have doubts related to mouthrinse posology. It is important to consider that the expected benefits will not be reached following a wrong clinical scheme of mouthrinse use. After checking the labels, the authors looked for directions on $\mathrm{CHX}$ rinsing duration in the available literature. The information found was inconsistent since different researchers aimed at evaluating CHX in different posology schemes. ${ }^{13}$

As mentioned before, there were discrepancies in terms of the selected mouthrinse and its recommendation for long- or short-term use. CHX is an effective mouthrinse for short-term use because, after a few weeks of consecutive use, it may lead to oral adverse events. ${ }^{63}$ Therefore, $\mathrm{CHX}$ has been recommended in different clinical situations such as pre-procedure ${ }^{64}$ and post-surgical periods. ${ }^{65} \mathrm{In}$ addition, because an increased anti-plaque effectiveness of CHX is only observed when used after an interval $\geq 30$ minutes between toothbrushing and rinsing, patients' compliance is difficult to achieve in the long-term, ${ }^{66}$ especially when we consider that eating, chewing or drinking after rinsing would also decrease CHX substantivity. ${ }^{13}$ On the other hand, longitudinal studies that evaluated EO have demonstrated that improvements in clinical parameters observed after 3 months tend to increase over 6 months, showing that their regular long-term use provides more benefits to patients. ${ }^{67,68,69,70}$ Although, EO are mainly indicated for long-term use, especially to prevent and control plaque and gingivitis, it has also proven an option for sporadic short-term use such as a pre-procedural rinse. ${ }^{71}$ Moreover, its long-term use is also supported by the lack of adverse events. In a systematic review published by Stoeken et al. ${ }^{36}$ it was demonstrated that most studies agreed that EO did not produce more tooth-staining than the control products. Some manufacturers indicate CPC long-term use; however, published articles failed to support this indication. CPC benefits observed in 6-month studies are primarily concentrated in the initial 3 months. Plaque and gingivitis reductions observed at 3 months were similar to those observed at 6 months. However, in some studies CPC reductions did not remain from 3 to 6 months. ${ }^{67,70,72,73}$ On this topic, the consulted scientific literature clarified the short- or long-term recommendation. Today, there is no doubt about CHX and EO length of use; for CPC, data is more inconclusive and should be interpreted with caution.

Still considering the adequate use of a mouthrinse, it is relevant to mention that all participants indicated the use of a mouthrinse after toothbrushing (and not before it). The literature is in agreement with these answers. Besides any possible interactions, such as that mentioned before related to $\mathrm{CHX}$ use, chemical agents seem to be more effective when used after brushing. Zanatta et al. ${ }^{74}$ demonstrated a reduced efficacy against plaque and gingivitis on tooth surfaces covered by a well structured biofilm. Unfortunately, among interviewees who do not recommend mouthrinses, no one was able to explain why.

\section{Effectiveness and expected benefits of mouthrinses}

All dentists reported that mouthrinses could be a complement to mechanical plaque control. The literature supports these answers. Antiseptics should be used in conjunction with mechanical plaque control. Although antiseptics show different levels of efficacy, gingival inflammation was observed in patients under exclusive chemical plaque control composed of $\mathrm{CHX},{ }^{75} \mathrm{EO}$ or CPC. ${ }^{76}$ In addition, among gingivitis patients, the greatest plaque and gingival inflammation reductions were observed for those who flossed, brushed and used an EO mouthrinse regularly in comparison to those who used less complete oral care regimens. ${ }^{69}$

Another discrepancy was observed regarding expected oral benefits. Although $64 \%$ of the dentists answered that they knew very little about the efficacy and also about the benefits $(54 \%)$ provided by mouthrinses, $90 \%$ reported to be aware of their anti-plaque properties, and $73 \%$ acknowledged their anti-gingivitis properties. Even though they 
were not sure about the efficacy of mouthrinses, $90 \%$ answered that a systemic condition could justify their use, probably because all $(100 \%)$ interviewees believe that oral health impacts overall systemic health. Interestingly, $45 \%$ expected some systemic benefit from mouthrinse use.

Reductions in the amount of plaque and in the degree of inflammation are the best documented clinical oral benefits provided by mouthrinse use. ${ }^{8,12}$ In addition, shifts in microbial profile and reductions in specific pathogens were also found..$^{77,78}$ Monitoring of other inflammatory indicators confirmed the anti-inflammatory properties of antiseptics. ${ }^{11,79}$

Dentists were asked whether they knew if one product was superior to others. Forty five percent did not know whether superiority among mouthrinses exists or not. The other $55 \%$ answered that $\mathrm{CHX}$ and EO are superior in comparison to others. Once again, these last answers are consistent with the available scientific data on short- and long-term uses, respectively. CHX has shown good anti-plaque and anti-gingivitis properties when used for chemical plaque control. ${ }^{8,74} \mathrm{EO}$ has also been proven to provide significant effects against plaque and gingivitis. ${ }^{36,80}$ Under specific clinical conditions, EO showed comparable results to those of CHX. ${ }^{81}$ One important aspect that certainly contributes to this superiority is their ability to penetrate biofilms. Research analysis showed that $\mathrm{CHX}$ and $\mathrm{EO}^{82}$ penetrated biofilm, and were effective in reducing bacteria living in it. ${ }^{83}$ Although rinsing is more effective against supragingival biofilm, microbial improvements in subgingival microbiota were also observed following EO use. ${ }^{9,10}$

$\mathrm{EO}$ and CPC provide different levels of oral benefits. ${ }^{70,73,76}$ Although less effective than EO, the use of a CPC mouthrinse seems to be better than brushing alone, reinforcing the indication of mouthrinses for chemical plaque control. ${ }^{84}$ Of course, in most cases, the cost-benefit ratio will support the prescription of more effective products. Therefore, professionals should alert patients about the investment, expectations and limitations of any oral care regimen.

Oral health has surpassed the mouth limits because oral status is associated with general health indicators. As described earlier, poor periodontal status negatively impacts the quality of life. In addition, periodontal pathogens which primarily colonize oral sites were identified in different systemic sites, such as atherosclerotic plaques from coronary arteries, ${ }^{85}$ preterm delivery placenta ${ }^{86}$ and stomach of morbid obese individuals. ${ }^{87}$ Effective mouthrinses such as those containing EO reduced the occurrence of bacteremia ${ }^{88}$ which could lead to adverse systemic events in susceptible individuals. CHX has been used to reduce the development of pneumonia in patients in intensive care units. ${ }^{62}$ Therefore, considering the mouth as part of the body, a healthier mouth will positively impact the rest of the body.

\section{Mouthrinse safety information}

Seventy two percent of interviewees reported that everyone could use mouthrinses. Although no restriction related to age was given, mouthrinse labels gave specific information related to the non-indication for children up to 12 years.

Most participants (75\%) answered that the use of mouthrinses is safe, which is consistent with the literature. The other $25 \%$ had no information or were concerned mainly with two aspects: bacterial resistance and alcohol and oral cancer. According to Santos ${ }^{89}$ and Teles and Teles, ${ }^{12}$ the short-term use of CHX and long-term use of EO are microbiologically safe, with no changes observed in the bacterial composition of supragingival plaque, and no evidence of microbial resistance. In relation to alcohol-containing mouthrinses, there is no scientific evidence to support the professionals' concern. Lemos Jr and Villoria ${ }^{90}$ reviewed the literature and concluded that alcohol-containing mouthrinses are safe and should be part of a comprehensive oral health care regimen. The same conclusions were demonstrated in a systematic review published by Silverman and Wilder. ${ }^{91}$ The ethanol present in mouthrinses does not contain the carcinogens found in alcoholic beverages, and ethanol has never been demonstrated to be carcinogenic either in laboratory animals or in humans. ${ }^{92,90}$ Therefore, the literature does not support dentists' concerns observed in the present survey.

Dentists who recommended mouthrinses to their patients frequently recommended them to their family members or people they love (63\%). However, 
most participants $(55 \%)$ did not declare themselves as mouthrinse users. In addition, among users, $45 \%$ used mouthrinses only sporadically. Together, these last answers confirm the lack of a more thorough knowledge about the investigated subject, indicate that participants were not highly confident about the use of mouthrinses, and suggest the need for specific educational strategies.

\section{Conclusions}

Based on the answers to the focus question, the authors concluded that dentists in different levels of dental education have only partial knowledge related to mouthrinse use in periodontics. Many answers given to both subsequent hierarchical levels of questions were consistent with and supported by scien-

\section{References}

1. Salvi GE, Della Chiesa A, Kianpur P, Attström R, Schmidlin $\mathrm{K}$, Zwahlen $\mathrm{M}$, et al. Clinical effects of interdental cleansing on supragingival biofilm formation and development of experimental gingivitis. Oral Health Prev Dent. 2009;7(4):38391

2. Hugoson A, Norderyd O. Has the prevalence of periodontitis changed during the last 30 years? J Clin Periodontol. 2008 Sep;35(8 Suppl):338-45.

3. Li Y, Lee S, Hujoel P, Su M, Zhang W, Kim J, et al. Prevalence and severity of gingivitis in American adults. Am J Dent. 2010 Feb;23(1):9-13.

4. Bader HI. Floss or die: implications for dental professionals. Dent Today. 1998 Jul;17(7):76-8, 80-2.

5. Buglar ME, White KM, Robinson NG. The role of self-efficacy in dental patients' brushing and flossing: testing an extended Health Belief Model. Patient Educ Couns. 2010 Feb;78(2):269-72.

6. Ramsay DS. Patient compliance with oral hygiene regimens: a behavioural self-regulation analysis with implications for technology. Int Dent J. 2000;Suppl Creating A Successful:30411.

7. Barnett ML. The rationale for the daily use of an antimicrobial mouthrinse. J Am Dent Assoc. 2006 Nov;137 Suppl:16S21S.

8. Gunsolley JC. A meta-analysis of six-month studies of antiplaque and antigingivitis agents. J Am Dent Assoc. 2006 Dec;137(12):1649-57.

9. Fine DH, Markowitz K, Furgang D, Goldsmith D, Charles $\mathrm{CH}$, Lisante TA, et al. Effect of an essential oil-containing antimicrobial mouthrinse on specific plaque bacteria in vivo. J Clin Periodontol. 2007 Aug;34(8):652-7. tific literature. Some doubts revealed by the questions in this survey require efforts from researchers and manufacturers to provide clearer information to dental professionals. However, other doubts require efforts from dentists themselves considering that there is appropriate scientific information available.

Many antiseptics are commercially available with different profiles of clinical indication. Few of them are superior to others and are able to provide greater benefits. Patients' needs and the cost-benefit ratio should be considered for mouthrinse choice. The use of effective mouthrinses on a daily basis is justified and will help patients to achieve or maintain a healthier mouth. A healthier mouth will positively impact patients' quality of life and could benefit their overall systemic health.

10. Fine DH, Markowitz K, Furgang D, Goldsmith D, Ricci-Nittel $\mathrm{D}$, Charles $\mathrm{CH}$, et al. Effect of rinsing with an essential oilcontaining mouthrinse on subgingival periodontopathogens. J Periodontol. 2007 Oct;78(10):1935-42.

11. Cortelli SC, Cortelli JR, Holzhausen M, Franco GC, Rebelo RZ, Sonagere AS, et al. Essential oils in one-stage full-mouth disinfection: double-blind, randomized clinical trial of longterm clinical, microbial and salivary effects. J Clin Periodontol. 2009 Apr;36(4):333-42.

12. Teles RP, Teles FR. Antimicrobial agents used in the control of periodontal biofilms: effective adjuncts to mechanical plaque control? Braz Oral Res. 2009;23 Suppl 1:39-48.

13. Tomás I, Cousido MC, García-Caballero L, Rubido S, Limeres J, Diz P. Substantivity of a single chlorhexidine mouthwash on salivary flora: influence of intrinsic and extrinsic factors. J Dent. 2010 Jul;38(7):541-6.

14. Fenesy KE. Periodontal disease: an overview for physicians. Mt Sinai J Med. 1998 Oct-Nov;65(5-6):362-9.

15. Kinane D, Bouchard P, Group E of European Workshop on Periodontology. Periodontal diseases and health: Consensus Report of the Sixth European Workshop on Periodontology. J Clin Periodontol. 2008 Sep;35(8 Suppl):333-7.

16. Weidlich P, Cimões R, Pannuti CM, Oppermann RV. Association between periodontal diseases and systemic diseases. Braz Oral Res. 2008;22 Suppl 1:32-43

17. Seymour RA. Is gum disease killing your patient? Br Dent J. 2009 May 23;206(10):551-2.

18. Seymour RA. Does periodontal treatment improve general health? Dent Update. 2010 May;37(4):206-8, 210-2. 
19. Naito M, Yuasa H, Nomura Y, Nakayama T, Hamajima N, Hanada N. Oral health status and health-related quality of life: a systematic review. J Oral Sci. 2006; 48(1):1-7.

20. Patel RR, Richards PS, Inglehart MR. Periodontal health, quality of life, and smiling patterns--an exploration. J Periodontol. 2008 Feb;79(2):224-31.

21. Araujo AC, Gusmao ES, Batista JE, Cimoes R. Impact of periodontal disease on quality of life. Quintessence Int. 2010 Jun;41(6):e111-8.

22. Amaral Loureiro AC, Oliveira Costa F, Eustáquio da Costa J. The impact of periodontal disease on the quality of life of individuals with Down syndrome. Downs Syndr Res Pract. 2007 Jul;12(1):50-4.

23. Ereshefsky M. Defining 'health' and 'disease'. Stud Hist Philos Biol Biomed Sci. 2009 Sep;40(3):221-7

24. Gillon R. On sickness and on health. Br Med J (Clin Res Ed). 1986 Feb 1;292(6516):318-20.

25. Blinkhorn A, Bartold PM, Cullinan MP, Madden TE, Marshall RI, Raphael SL, et al. Is there a role for triclosan/copolymer toothpaste in the management of periodontal disease? Br Dent J. 2009 Aug 8;207(3):117-25.

26. Haraszthy VI, Zambon JJ, Sreenivasan PK. The antimicrobial efficacy of commercial dentifrices. Gen Dent. 2010 JanFeb;58(1):50-5; quiz 56-7, 79-80.

27. Pope C, Mays N. Reaching the parts other methods cannot reach: an introduction to qualitative methods in health and health services research. BMJ. 1995 Jul 1;311(6996):42-5.

28. Huston P, Rowan M. Qualitative studies. Their role in medical research. Can Fam Physician. 1998 Nov;44:2453-8.

29. Paraskevas S, Danser MM, Timmerman MF, van der Velden $\mathrm{U}$, van der Weijden GA. Amine fluoride/stannous fluoride and incidence of root caries in periodontal maintenance patients. A 2 year evaluation. J Clin Periodontol. 2004 Nov;31(11):96571.

30. de Soete M, Dekeyser C, Pauwels M, Teughels W, van Steenberghe D, Quirynen M. Increase in cariogenic bacteria after initial periodontal therapy. J Dent Res. 2005 Jan;84(1):48-53.

31. Müller HP, Barrieshi-Nusair KM, Könönen E, Yang M. Effect of triclosan/copolymer-containing toothpaste on the association between plaque and gingival bleeding: a randomized controlled clinical trial. J Clin Periodontol. 2006 Nov;33(11):8118

32. Axelsson P, Albandar JM, Rams TE. Prevention and control of periodontal diseases in developing and industrialized nations. Periodontol 2000. 2002;29:235-46.

33. Wilson TG Jr. How patient compliance to suggested oral hygiene and maintenance affect periodontal therapy. Dent Clin North Am. 1998 Apr;42(2):389-403.

34. Sharma NC, Charles CH, Qaqish JG, Galustians HJ, Zhao Q, Kumar LD. Comparative effectiveness of an essential oil mouthrinse and dental floss in controlling interproximal gingivitis and plaque. Am J Dent. 2002 Dec;15(6):351-5.
35. Zimmer S, Kolbe C, Kaiser G, Krage T, Ommerborn M, Barthel C. Clinical efficacy of flossing versus use of antimicrobial rinses. J Periodontol. 2006 Aug;77(8):1380-5.

36. Stoeken JE, Paraskevas S, van der Weijden GA. The longterm effect of a mouthrinse containing essential oils on dental plaque and gingivitis: a systematic review. J Periodontol. 2007 Jul;78(7):1218-28. Review.

37. Brothwell DJ, Jutai DK, Hawkins RJ. An update of mechanical oral hygiene practices: Evidence-based recommendations for disease prevention. J Can Dent Assoc. 1998 Apr;64(4):295306.

38. Davies RM, Davies GM, Ellwood RP. Prevention. Part 4: Toothbrushing: What advice should be given to patients? $\mathrm{Br}$ Dent J. 2003 Aug 9;195(3):135-41.

39. Marchini L, Vieira PC, Bossan TP, Montenegro FL, Cunha VP. Self-reported oral hygiene habits among institutionalised elderly and their relationship to the condition of oral tissues in Taubaté, Brazil. Gerodontology. 2006 Mar;23(1):33-7.

40. Davoglio RS, Aerts DR, Abegg C, Freddo SL, Monteiro L. Factors associated with oral health habits and use of dental services by adolescents. Cad Saude Publica. 2009 Mar;25(3):65567.

41. Hugoson A, Koch G, Bergendal T, Hallonsten AL, Slotte C, Thorstensson B, et al. Oral health of individuals aged 3-80 years in Jönköping, Sweden in 1973, 1983, and 1993. I. Review of findings on dental care habits and knowledge of oral health. Swed Dent J. 1995;19(6):225-41.

42. Paulander J, Axelsson P, Lindhe J. Association between level of education and oral health status in 35-, 50-, 65- and 75year-olds. J Clin Periodontol 2003 Aug;30(8):697-704.

43. Neamatollahi H, Ebrahimi M. Oral health behavior and its determinants in a group of Iranian students. Indian J Dent Res. 2010 Jan-Mar;21(1):84-8.

44. Kirtiloglu T, Yavuz US. An assessment of oral self-care in the student population of a Turkish university. Public Health. 2006 Oct;120(10):953-7.

45. Boyer EM, Nikias MK. Self-reported compliance with a preventive dental regimen. Clin Prev Dent. 1983 Jan-Feb;5(1):37.

46. Renz A, Ide M, Newton T, Robinson PG, Smith D. Psychological interventions to improve adherence to oral hygiene instructions in adults with periodontal diseases. Cochrane Database Syst Rev. 2007 Apr 18;(2):CD005097.

47. Dumitrescu AL, Kawamura M, Dogaru BC, Dogaru CD. Self-reported oral health status, oral health-related behaviours, resilience and hope in Romania. Oral Health Prev Dent. 2009;7(3):251-9.

48. Collins LM, Dawes C. The surface area of the adult human mouth and thickness of the salivary film covering the teeth and oral mucosa. J Dent Res. 1987 Aug;66(8):1300-2.

49. Kerr WJS, Kelly J, Geddes DAM. The Areas of Various Surfaces in the Human Mouth from Nine Years to Adulthood. J Dent Res. 1991 Dec;70(12):1528-30. 
50. Cortelli JR, Aquino DR, Cortelli SC, Fernandes CB, de Carvalho-Filho J, Franco GC, et al. Etiological analysis of initial colonization of periodontal pathogens in oral cavity. J Clin Microbiol. 2008 Apr;46(4):1322-9

51. Oredugba FA, Akindayomi Y. Oral health status and treatment needs of children and young adults attending a day centre for individuals with special health care needs. BMC Oral Health. 2008 Oct 22;8:30.

52. Albandar JM. Global risk factors and risk indicators for periodontal diseases. Periodontol 2000. 2002;29:177-206.

53. Albandar JM, Tinoco EM. Global epidemiology of periodontal diseases in children and young persons. Periodontol 2000. 2002;29:153-76.

54. Laing E, Ashley P, Gill D, Naini F. An update on oral hygiene products and techniques. Dent Update. 2009 Sep;36(7):439.

55. Gagliardi DI, Slade GD, Sanders AE. Impact of dental care on oral health-related quality of life and treatment goals among elderly adults. Aust Dent J. 2008 Mar;53(1):26-33.

56. Blaizot A, Vergnes JN, Nuwwareh S, Amar J, Sixou M. Periodontal diseases and cardiovascular events: meta-analysis of observational studies. Int Dent J. 2009 Aug;59(4):197-209.

57. Khader YS, Albashaireh ZS, Hammad MM. Periodontal status of type 2 diabetics compared with nondiabetics in north Jordan. East Mediterr Health J. 2008 May-Jun;14(3):65461.

58. Awano S, Ansai T, Takata Y, Soh I, Akifusa S, Hamasaki T, et al. Oral health and mortality risk from pneumonia in the elderly. J Dent Res. 2008 Apr;87(4):334-9.

59. Chávarry NG, Vettore MV, Sansone C, Sheiham A. The relationship between diabetes mellitus and destructive periodontal disease: a meta-analysis. Oral Health Prev Dent. 2009; 7(2):107-27.

60. de Oliveira C, Watt R, Hamer M. Toothbrushing, inflammation, and risk of cardiovascular disease: results from Scottish Health Survey. BMJ. 2010 May 27;340:c2451

61. Fujita M, Ueno K, Hata A. Lower frequency of daily teeth brushing is related to high prevalence of cardiovascular risk factors. Exp Biol Med (Maywood). 2009 Apr;234(4):38794.

62. Carvajal C, Pobo A, Díaz E, Lisboa T, Llauradó M, Rello J. Oral hygiene with chlorhexidine on the prevention of ventilator-associated pneumonia in intubated patients: A systematic review of randomized clinical trials. Med Clin (Barc). 2010 Jun 15. DOI:10.1016/j.medcli.2010.02.039.

63. McCoy LC, Wehler CJ, Rich SE, Garcia RI, Miller DR, Jones JA. Adverse events associated with chlorhexidine use. J Am Dent Assoc. 2008 Feb;139(2):178-83.

64. Veksler AE, Kayrouz GA, Newman MG. Reduction of salivary bacteria by pre-procedural rinses with chlorhexidine $0.12 \%$. J Periodontol. 1991 Nov;62(11):649-51.

65. Heitz F, Heitz-Mayfield LJ, Lang NP. Effects of post-surgical cleansing protocols on early plaque control in periodontal and/or periimplant wound healing. J Clin Periodontol. 2004 Nov;31(11):1012-8.

66. Kolahi J, Soolari A. Rinsing with chlorhexidine gluconate solution after brushing and flossing teeth: a systematic review of effectiveness. Quintessence Int. 2006 Sep;37(8):605-12.

67. Charles CH, Sharma NC, Galustians HJ, Qaqish J, McGuire JA, Vincent JW. Comparative efficacy of an antiseptic mouthrinse and an antiplaque/antigingivitis dentifrice. A six-month clinical trial. J Am Dent Assoc. 2001 May;132(5):670-5.

68. Charles C, Simmons K, Amini P, Qaqish JG, Sharma N. Increasing antiplaque/antigingivitis efficacy of an essential oil mouthrinse over time - an in vivo study. $28^{\circ}$ Congresso Internacional de Odontologia de São Paulo; 30 jan - 3 feb 2010; São Paulo, BR. Anais eletrônicos. Available on http://www. ciosp.com.br/anais_28ciosp.htm.

69. Sharma N, Charles CH, Lynch MC, Qaqish J, McGuire JA, Galustians JG, et al. Adjunctive benefit of an essential oilcontaining mouthrinse in reducing plaque and gingivitis in patients who brush and floss regularly: a six-month study. J Am Dent Assoc. 2004 Apr;135(4):496-504.

70. Cortelli SC, Simmons K, Cortelli JR, Wu M-M, Araujo MWB, Charles C. Long-term superiority: combination essential-oils compared to $0.05 \%$ CPC rinse [abstract]. The 88th General Session \& Exhibition of the IADR, Barcelona, Spain, jul 1417, 2010. Abstract 443, p 83.

71. Yengopal V. The use of essential oil mouthwashes as preprocedural rinses for infection control. SADJ. 2004 Jul;59(6):247-8, 250

72. Stookey GK, Beiswanger B, Mau M, Isaacs RL, Witt JJ, Gibb R. A 6-month clinical study assessing the safety and efficacy of two cetylpyridinium chloride mouthrinses. Am J Dent. 2005;18 Spec No:24A-28A.

73. Sharma NC, Araujo MWB, Wu M-M, Qaqish J, Charles CH. Superiority of an essential oil mouthrinse when compared with a $0.05 \%$ cetylpyridinium chloride containing mouthrinse: a six-month study. Int Dent J. 2010 May;60(3):175-80.

74. Zanatta FB, Antoniazzi RP, Rösing CK. The effect of $0.12 \%$ chlorhexidine gluconate rinsing on previously plaque-free and plaque-covered surfaces: a randomized, controlled clinical trial. J Periodontol. 2007 Nov;78(11):2127-34.

75. Franco Neto CA, Parolo CC, Rösing CK, Maltz M. Comparative analysis of the effect of two chlorhexidine mouthrinses on plaque accumulation and gingival bleeding. Braz Oral Res. 2008 Apr-Jun;22(2):139-44.

76. Amini P, Araujo MW, Wu MM, Charles CA, Sharma NC. Comparative antiplaque and antigingivitis efficacy of three antiseptic mouthrinses: a two week randomized clinical trial. Braz Oral Res. 2009 Jul-Sep;23(3):319-25.

77. Fine DH, Furgang D, Sinatra K, Charles C, McGuire A, Kumar LD. In vivo antimicrobial effectiveness of an essential oil-containing mouth rinse $12 \mathrm{~h}$ after a single use and 14 days' use. J Clin Periodontol. 2005 Apr;32(4):335-40 
78. Haffajee AD, Roberts C, Murray L, Veiga N, Martin L, Teles RP, et al. Effect of herbal, essential oil, and chlorhexidine mouthrinses on the composition of the subgingival microbiota and clinical periodontal parameters. J Clin Dent. 2009;20(7):211-7.

79. Sharma S, Saimbi CS, Koirala B, Shukla R. Effect of various mouthwashes on the levels of interleukin-2 and interferongamma in chronic gingivitis. J Clin Pediatr Dent. 2008 Winter;32(2):111-4

80. Patel RM, Malaki Z. The effect of a mouthrinse containing essential oils on dental plaque and gingivitis. Evid Based Dent. 2008;9(1):18-9.

81. Charles CH, Mostler KM, Bartels LL, Mankodi SM. Comparative antiplaque and antigingivitis effectiveness of a chlorhexidine and an essential oil mouthrinse: 6-month clinical trial. J Clin Periodontol. 2004 Oct;31(10):878-84.

82. Ouhayoun JP. Penetrating the plaque biofilm: impact of essential oil mouthwash. J Clin Periodontol. 2003;30 Suppl 5:10-2.

83. Fine DH, Furgang D, Barnett ML. Comparative antimicrobial activities of antiseptic mouthrinses against isogenic planktonic and biofilm forms of Actinobacillus actinomycetemcomitans. J Clin Periodontol. 2001 Jul;28(7):697-700.

84. Haps S, Slot DE, Berchier CE, Van der Weijden GA. The effect of cetylpyridinium chloride-containing mouth rinses as adjuncts to toothbrushing on plaque and parameters of gingival inflammation: a systematic review. Int J Dent Hyg. 2008 Nov;6(4):290-303.
85. Gaetti-Jardim Jr E, Marcelino SL, Feitosa AC, Romito GA, Avila-Campos MJ. Quantitative detection of periodontopathic bacteria in atherosclerotic plaques from coronary arteries. J Med Microbiol. 2009 Dec;58(Pt 12):1568-75. Epub 2009 Aug 13.

86. Katz J, Chegini N, Shiverick KT, Lamont RJ. Localization of P. gingivalis in preterm delivery placentas. J Dent Res. 2009 Jun;88(6):575-8.

87. Pataro AL. Associação entre obesidade e condição periodontal: análise epidemiológica e microbiológica em indivíduos obesos, candidatos e submetidos à cirurgia bariátrica. [tese]. Belo Horizonte: Universidade Federal de Minas Gerais, Faculdade de Odontologia; 2010.

88. Fine DH, Korik I, Furgang D, Myers R, Olshan A, Barnett ML, et al. Assessing pre-procedural subgingival irrigation and rinsing with an antiseptic mouthrinse to reduce bacteremia. J Am Dent Assoc. 1996 May;127(5):641-2, 645-6.

89. Santos A. Evidence-based control of plaque and gingivitis. J Clin Periodontol. 2003;30 Suppl 5:13-6.

90. Lemos-Júnior CA, Villoria GEM. Reviewed evidence about the safety of the daily use of alcohol-based mouthrinses. Braz Oral Res. 2008;22 Suppl 1:24-31.

91. Silverman Jr S, Wilder R. Antimicrobial mouthrinse as part of a comprehensive oral care regimen. J Am Dent Assoc. 2006 Nov;137 Suppl:22S-26S.

92. Claffey N. Essential oil mouthwashes: a key component in oral health management. J Clin Periodontol. 2003;30 Suppl $5: 22-4$. 